\title{
The Flight Physiology of Reproductives of Africanized, European, and Hybrid Honeybees (Apis mellifera)
}

\author{
Jon F. Harrison ${ }^{1, *}$ \\ Orley R. Taylor Jr. ${ }^{2, \dagger}$ \\ H. Glenn Hall ${ }^{3, \neq}$ \\ ${ }^{1}$ School of Life Sciences, Arizona State University, Tempe, \\ Arizona 85287-4501; ${ }^{2}$ Division of Biological Sciences, \\ University of Kansas, Hayworth Hall, Room 7005, 1200 \\ Sunnyside Avenue, Lawrence, Kansas 66045-7534; \\ ${ }^{3}$ Department of Entomology and Nematology, University of \\ Florida, 3112 Eyn, Gainesville, Florida 32611
}

Accepted 6/28/04; Electronically Published 2/25/05

\section{ABSTRACT}

Neotropical African honeybees (Apis mellifera scutellata), in the process of spreading throughout tropical and subtropical regions of the Americas, hybridize with and mostly replace European honeybees (primarily Apis mellifera mellifera and Apis mellifera ligustica). To help understand this process, we studied the effect of lineage (African, European, or hybrid) on the flight physiology of honeybee reproductives. Flight metabolic rates were higher in queens and drones of African lineage than in European or hybrid bees, as has been previously found for foraging workers. These differences were associated with higher thorax/body mass ratios and higher thorax-specific metabolic rates in African lineage bees. Queens were reared in common colonies, so these metabolic and morphological differences are likely to be genetic in origin. African drones had higher wing beat frequencies and thorax temperatures than European or hybrid bees. Hybrids were intermediate for many parameters, but hybrid queen mass-specific flight metabolic rates were low relative to Africans and were nonlinearly affected by the proportion of African lineage, consistent with some negative heterosis for this trait.

\footnotetext{
*E-mail: j.harrison@asu.edu.

${ }^{\dagger}$ E-mail: chip@mail.ku.edu.

${ }^{\ddagger}$ E-mail: hgh@ifas.ufl.edu.
}

Physiological and Biochemical Zoology 78(2):153-162. 2005. (c) 2005 by The University of Chicago. All rights reserved. 1522-2152/2005/7802-3172\$15.00

\section{Introduction}

A central question in ecological and evolutionary physiology is understanding the significance of intraspecific variation in physiological traits (Garland and Carter 1994). Invasive populations are potentially very useful for understanding the significance of physiological variation because the fitness advantages of the invading population are often evident. The spread of Neotropical African honeybees (NAHB; Apis mellifera scutellata, Lipeletier) has been one of the more spectacular and publicized examples of an ecological invasion (Taylor 1985; Spivak et al. 1990; Winston 1992a). The NAHB reproduce (swarm) more rapidly than eastern European honeybees (EHB; Apis mellifera ligustica, L.; Winston 1992a, 1992b). These greater reproductive rates are correlated with smaller colony sizes and a tendency for faster developmental rates, shorter life spans, and greater pollen collection (reviewed by Winston 1992a, 1992b; Harrison and Fewell 2002). However, the physiological factors that allow the NAHB to grow and reproduce at higher rates than $\mathrm{EHB}$ remain unclear.

One identified physiological difference that could contribute to the ecological variation between NAHB and EHB is flight metabolic rate. NAHB have higher body and thorax massspecific metabolic rates than EHB when assayed in a coldexposed swarm (Southwick 1990) and during flight (Harrison and Hall 1993; Fewell and Harrison 2002). When NAHB and $\mathrm{EHB}$ are reared in a single colony, foraging-age NAHB workers had higher flight metabolic rates and foraging trip frequencies than EHB workers, suggesting that higher flight metabolic rates might lead to faster colony growth rates by supporting greater worker foraging effort (Fewell and Harrison 2002). Alternatively, the higher flight metabolic rates of NAHB might simply be due to greater behavioral activation of NAHB in the flight assay because their greater defensive behavior might lead to more vigorous flight when captured. Queens and drones do not exhibit defensive behavior, so if the metabolic differences between NAHB and EHB are related to differences in defensive reactions, flight metabolic rates should not differ among NAHB and EHB reproductives. Therefore, in this study, we examine the effect of NAHB or EHB lineage on the flight metabolic rate of honeybee reproductives.

In addition, many aspects of the ecological success of a honeybee race may depend on flight physiology of the reproductives (e.g., male mating success, queen dispersal ability) rather than the workers. Since their introduction into the Neotropics in the 1950s, NAHB have successfully colonized a large portion 
of the tropical and subtropical Americas, in most cases replacing the EHB (primarily A. m. ligustica and Apis mellifera mellifera) that were present (Michener 1975; Winston 1992a). The colonization has occurred primarily by the spreading of maternal lineages (swarms; Hall and Muralidharan 1989; Smith et al. 1989; Hall 1992a). There are suggestive data that the rapid spread of NAHB swarms has been assisted by a tendency for African swarms to disperse farther than European swarms (Schneider 1995). We hypothesized that NAHB queens would have higher flight metabolic rates than EHB queens because a higher flight metabolic rate might contribute to the greater dispersal capacity of African swarms. In addition, mating behavior between NAHB and EHB is at least partially nonrandom, with reports of partial assortative mating (Kerr and Bueno 1970) and also reports of NAHB drones mating extensively with EHB queens but with relatively little mating between NAHB queens and EHB drones (Taylor 1999). We hypothesized that NAHB queens and drones would have higher flight metabolic rates than EHB reproductives because these could support greater flight performance during mating flights for NAHB bees.

Hybridization between African and European honeybees occurs during the initial years of colonization of an area by African bees (Rinderer et al. 1991; Sheppard et al. 1991), and European and hybrid genotypes persist in higher altitude and latitude regions where African bees have difficulties overwintering (Lobo et al. 1989; Del Lama et al. 1990; Sheppard et al. 1991). However, in lower-latitude and lower-altitude regions, after a period of time, the honeybees present are virtually completely African, as judged by mitochondrial DNA, and highly Africanized, on the basis of nuclear DNA (Hall 1986, 1992b; Hall and Muralidharan 1989; Smith et al. 1989; Hall and Smith 1991; McMichael and Hall 1996; Suazo et al. 1998). The mechanism by which the apparent elimination of African-European hybrids occurs is unclear. Predominance of nearly pure African bees may occur by simple numerical swamping because of the much higher reproductive rate of African bees (Page 1989). Also, African-European hybrids may be less than intermediate in fitness between the parental types because of nonadditive genetic effects (Hall and Muralidharan 1989). In support of this hypothesis, African-European hybrid workers have low, nonintermediate agitated flight metabolic rates (Harrison and Hall 1993) and developmental rates (DeGrandi-Hoffman et al. 1998). In this study, we tested the flight metabolic rates of African-European hybrid reproductives to further test the hypothesis of negative heterosis in African-European crosses.

One significant problem with interpreting our previous study of the flight physiology of African, European, and hybrid workers was that workers were reared either in their natal colony (Harrison and Hall 1993) or after adult eclosion in a common colony (Fewell and Harrison 2002). Colony environment (African vs. European) can have a strong effect on the foraging behavior and life span of African and European honeybees
(Winston and Katz 1981, 1982) and can also affect metabolic rates (Harrison et al. 1996). Rearing adults in a single colony controls for some of these environmental effects, but strong effects of larval diet may remain. In this study, African, European, and hybrid queens were reared in common environments from the egg stage, so we were able to test whether metabolic rate differences occurred between these lineages independently of colony environment.

NAHB are smaller than EHB, and an important question is whether the differences in mass-specific flight metabolic rates are likely a result of simple mass-scaling effects. In this study, we measured total metabolic rate $(\mathrm{mW})$ and body mass-specific and thorax mass-specific metabolic rates $\left(\mathrm{mW} \mathrm{g}^{-1}\right)$ to characterize the potential for mass scaling to at least partially explain metabolic rate variation in NAHB and EHB queens and drones.

In summary, the main objectives of this study were to (1) test whether Africanized honeybee reproductives have higher metabolic rates, thorax temperatures, and wing beat frequencies during flight than Europeans; (2) examine factors that might account for metabolic differences among Africanized and European reproductives (e.g., mass scaling, thorax/body mass ratios); and (3) determine whether hybrids have intermediate flight metabolic rates. Our results indicate that African queens and drones do have higher metabolic rates during flight than Europeans, that these differences can be partially attributed to differences in thorax/body mass ratio and thorax-specific flight metabolic rate, and that some negative heterosis may occur for flight metabolism.

\section{Material and Methods}

\section{Animals}

This study was conducted in July 1993 near Linares, Nuevo Leon, Mexico. The NAHB stock queens were derived from swarms caught locally. All NAHB colonies showed typical morphology, behavior, and malate dehydrogenase and hexokinase phenotypes for this biotype and had measures across 10 linear worker cells of $4.9 \mathrm{~cm}$ or less (Spivak et al. 1988). All EHB stock used in these tests were reared from queens imported from Hawaii.

Queens were instrumentally inseminated with semen from multiple unrelated drones of known EHB or NAHB ancestry. The following abbreviations are used to describe the various lineages (the first letters indicate the maternal lineage, while the last letter indicates the paternal lineage): AA, offspring of African queen mated to African drone; EE, offspring of European queen mated to a European drone; AE, offspring of African queen mated to a European drone; EA, offspring of European queen mated to an African drone; AEA, offspring of daughter of an AE queen mated with an African drone; AEE, offspring of daughter of an AE queen mated with a European drone; EAE, offspring of daughter of an EA queen mated with a European drone; EAA, offspring of daughter of an EA queen 
mated with an African drone; AEAA, offspring of daughter of an AEA queen mated with an African drone; EAAA, offspring of daughter of an EAA queen mated with an African drone. It should be noted that honeybee drones are haploid and thus represent the genetic composition of their mother. Thus, an EA drone is not really a hybrid but is a haploid E, while EAA drones should be haploid EA, and so forth. Therefore, when discussing the drone lineages, we placed parentheses around the paternal contribution to help remind the reader that this paternal lineage should not contribute to the genetic composition of the drones.

To control for queen flight experience and to ensure that all queens were virgins, queens were caged from eclosion until the respirometric measurements. Drones' age and flight experience were not controlled and may have differed among the lines.

\section{Respirometry}

Respirometry measurements were made in a shaded outdoor laboratory. Because air temperature strongly affects flight metabolic rate in honeybees (Harrison et al. 1996), we attempted to regulate the temperature of the flight chambers by immersing them in an insulated water bath. We monitored and adjusted water bath and chamber temperature throughout the experiment. Drones were obtained as they flew out from hive entrances and were immediately transferred to a $0.3-\mathrm{L}$ Lucite respirometry chamber. Most drones hovered steadily within the chambers without provocation. Queens were removed from their rearing cages and flown for several minutes in a screen flight cage to allow them to defecate. Then, the queens were transferred to the respirometry chamber. After placement of the bee into the respirometry chamber, it was flushed for $1 \mathrm{~min}$ at $2 \mathrm{~L} \mathrm{~min}^{-1}$ with dry (Drierite), carbon dioxide-free (Ascarite) air. Average air velocity through the chamber was about $1 \mathrm{~cm}$ $\mathrm{s}^{-1}$. Queens generally hovered steadily near the top of the respirometry chamber. Flight metabolic rate was measured over $1 \mathrm{~min}$ of flight from carbon dioxide production using flowthrough respirometry as previously described (Harrison et al. 1996). Briefly, water vapor was removed from the air, leaving the respirometry chamber with a magnesium perchlorate column, and excurrent carbon dioxide was measured with a Licor 5152 carbon dioxide analyzer. The flow rate of air through the chamber was approximately $2 \mathrm{~L} \mathrm{~min}^{-1}$, measured to \pm 0.001 $\mathrm{L} \mathrm{min}^{-1}$ with an Omega mass flow meter. The analog output from the carbon dioxide analyzer was digitized and recorded with Sable Systems Datacan V (Las Vegas, NV) software and hardware. Any bees that did not fly steadily and continuously throughout the trial were excluded from the analysis. After respirometry, bees were shaken from the chamber, cooled on ice, weighed ( $\pm 0.1 \mathrm{mg}$ with a Mettler balance), and frozen for later allozyme analyses. Carbon dioxide production rates were converted to metabolic rates assuming that only carbohydrates are catabolized during flight (Rothe and Nachtigall 1989).

\section{Wing Beat Frequencies and Thorax Temperatures}

Wing beat frequencies were recorded with a microphone located inside the flight chamber (Harrison and Hall 1993) during the $15 \mathrm{~s}$ after respirometric measurements, with no air flow through the chamber. Tape recordings were digitized with SoundEdit and MacRecorder (Farallon Computing, Emeryville, $\mathrm{CA}$ ), and wing beat frequencies were calculated from the time period required for 10-20 wing beats. Because of investigator error (a microphone left off), successful wing beat recordings were not made for the queens. After wing beat frequency measurements, bees were shaken from the chamber and restrained against a styrofoam board with a plastic sheet. Thoracic temperatures were measured as quickly as possible after completion of the wing beat frequency measurements (usually within $3 \mathrm{~s}$, always within $10 \mathrm{~s}$ after opening the respirometry chamber) by inserting a Physitemp model MT-29/1 hypodermic microprobe (time constant $=0.025 \mathrm{~s}$ ) through the plastic sheet into the thorax.

\section{Allozymes}

NAHB and EHB differ strongly in their frequencies of alleles for malate dehydrogenase and hexokinase (Spivak et al. 1988), so allozyme analysis was performed on all bees in order to eliminate bees whose lineage might have been misidentified. The thoraxes were pulverized in extraction buffer, and the homogenates were run on a cellulose acetate gel and stained for hexokinase and malate dehydrogenase (Richardson et al. 1986). Six drones whose hexokinase and malate dehydrogenase phenotypes were inconsistent with the lineage of their hive (drones are known to drift between hives in an apiary) were eliminated from the study.

\section{Statistics}

All statistics were performed with SYSTAT 9 or 10 (Wilkinson 1989). Unless otherwise stated, general effects of genotype (African, European, or hybrid) for both queens and drones were tested by ANOVA, restricting the analyses to $\mathrm{AA}, \mathrm{EE}, \mathrm{AE}$, and EA groups to maintain sample sizes for each group larger than the number of groups. All genotypes were tested against the parental genotypes (AA and EE) by a priori comparisons, using the standard Bonferroni method to keep the overall experimentwise $P<0.05$. A priori comparisons are derived from the hypotheses before the results are examined. Thorax/body mass ratios were arcsine transformed before statistical analyses to better approximate a normal distribution. To test whether body mass explained the differences in flight metabolic rate between NAHB and EHB queens and drones, we used ANOVA with log metabolic rate as the dependent variable, log body mass as a covariate, and lineage as a factor. 


\section{Results}

\section{Chamber Temperatures}

Despite our efforts, flight chamber temperatures did differ significantly among the lineages (for queens: $F_{3,37}=2.89, P=$ 0.048; for drones: $F_{4,91}=10.7, P<0.001$; Table 1). Sample sizes for all groups are also presented in Table 1.

\section{Queens}

Body masses differed significantly among the lineages. Body mass was significantly affected by genotype $\left(F_{3,37}=5.00, P<\right.$ 0.005 ), with African queens $85 \%$ of the body mass of European queens and, thus, significantly smaller (Fig. 1). Hybrid queens were generally intermediate or similar to European queens in body mass, except for the AEE bees, which were significantly smaller than the European queens in body mass (Fig. 1).

Thorax mass was not significantly affected by genotype $\left(F_{3,37}=2.42, P=0.082\right)$. However, by a priori comparisons, African queens had significantly smaller thorax masses than EE bees (91\% of European values). As for body masses, hybrid queens were intermediate or similar to Europeans in thorax mass, except for the AEE queens, which were significantly smaller than the European queens (Fig. 1).

Thorax/body mass ratio was significantly affected by genotype $\left(F_{3,37}=2.85, P=0.05\right)$, with African queens having a significantly $7 \%$ higher thorax/body mass ratio than European queens (Fig. 1). Hybrid groups tended to be intermediate and not significantly different from either AA or EE bees, except that the EA bees had a significantly lower thorax/body mass ratio than AA bees and the EAAA bees had a significantly higher thorax/body mass ratio than EE bees (Fig. 1).

Thorax temperature was not significantly affected by genotype $(P>0.3$; Table 1$)$. None of the genotypes differed from the parental groups in thorax temperatures by the a priori comparisons of means. Thorax temperature also was not correlated with chamber temperature (Pearson's $R=0.11, P>$ $0.3)$.

Flight metabolic rates of queens were significantly affected by lineage (Fig. 2). Metabolic rate $\left(F_{3,50}=2.95, P=0.05\right)$, body mass-specific metabolic rate $\left(F_{3,50}=7.98, P<0.001\right)$, and thorax mass-specific metabolic rate $\left(F_{3,50}=4.49, P<0.01\right)$ were significantly affected by genotype. By a priori comparisons, African queens had significantly higher metabolic rates and body mass-specific and thorax mass-specific metabolic rates than EE queens (Fig. 2). AA queens had flight metabolic rates that were $14 \%, 37 \%$, and $27 \%$ higher than EE queens for milliwatts, milliwatts per gram body, and milliwatts per gram thorax, respectively. Hybrid lineages tended to have intermediate metabolic rates (Fig. 2); five of eight hybrid queens' genotypes had significantly lower body mass-specific metabolic rates than the AA queens (Fig. 2).

Body mass did not explain lineage effects on metabolic rate $(\mathrm{mW})$. With the ANOVA restricted to the AA, EE, AE, and EA

Table 1: Temperatures $\left({ }^{\circ} \mathrm{C}\right)$ of the flight chamber and thorax for the different lineages of honeybee queens and drones

\begin{tabular}{|c|c|c|c|c|}
\hline Lineage & $\begin{array}{l}\text { Chamber } \\
\text { Temperature } \\
\left({ }^{\circ} \mathrm{C}\right)\end{array}$ & $\begin{array}{l}\text { Thorax } \\
\text { Temperature } \\
\left({ }^{\circ} \mathrm{C}\right)\end{array}$ & $\begin{array}{l}\text { Wing Beat } \\
\text { Frequency } \\
(\mathrm{Hz})\end{array}$ & $\begin{array}{l}\text { Sample } \\
\text { Size }\end{array}$ \\
\hline \multicolumn{5}{|l|}{ Queens: } \\
\hline $\mathrm{A}(\mathrm{A})$ & $31.2 \pm$ & $43.3 \pm$ & NM & 10 \\
\hline $\mathrm{E}(\mathrm{E})$ & $31.0 \pm$ & $43.0 \pm .23$ & NM & 14 \\
\hline $\mathrm{A}(\mathrm{E})$ & $31.4 \pm .16$ & $43.0 \pm .36$ & NM & 11 \\
\hline $\mathrm{E}(\mathrm{A})$ & $28.6 \pm 1.91^{\mathrm{a}, \mathrm{b}}$ & $42.0 \pm .98$ & NM & 6 \\
\hline $\mathrm{AE}(\mathrm{A})$ & $29.0 \pm 1.41^{\mathrm{a}, \mathrm{b}}$ & $41.4 \pm 1.47$ & NM & 6 \\
\hline $\mathrm{AE}(\mathrm{E})$ & $31.4 \pm .36$ & $43.4 \pm .28$ & NM & 10 \\
\hline $\mathrm{EA}(\mathrm{E})$ & $31.9 \pm .16$ & $43.7 \pm .45$ & NM & 5 \\
\hline $\operatorname{AEA}(\mathrm{A})$ & $27.7 \pm 1.58^{\mathrm{a}, \mathrm{b}}$ & $40.5 \pm 1.49$ & NM & 6 \\
\hline $\mathrm{EAA}(\mathrm{A})$ & $31.3 \pm .21$ & $43.6 \pm .54$ & $\mathrm{NM}$ & 6 \\
\hline \multicolumn{5}{|l|}{ Drones: } \\
\hline $\mathrm{A}(\mathrm{A})$ & $30.7 \pm$ & $45.2 \pm$ & $235 \pm 6.3^{\mathrm{b}}$ & 23 \\
\hline $\mathrm{E}(\mathrm{E})$ & $30.9 \pm$ & $43.6 \pm$ & $218 \pm 4.8^{\mathrm{a}}$ & 20 \\
\hline $\mathrm{E}(\mathrm{A})$ & $30.7 \pm$ & $43.3 \pm$ & $199 \pm 7.3^{\mathrm{a}}$ & 8 \\
\hline $\mathrm{AE}(\mathrm{A})$ & $31.2 \pm$ & $44.4 \pm$ & $226 \pm 5.2$ & 27 \\
\hline $\mathrm{EA}(\mathrm{A})$ & $32.3 \pm$ & $44.1 \pm .38$ & $217 \pm 4.9$ & 18 \\
\hline
\end{tabular}



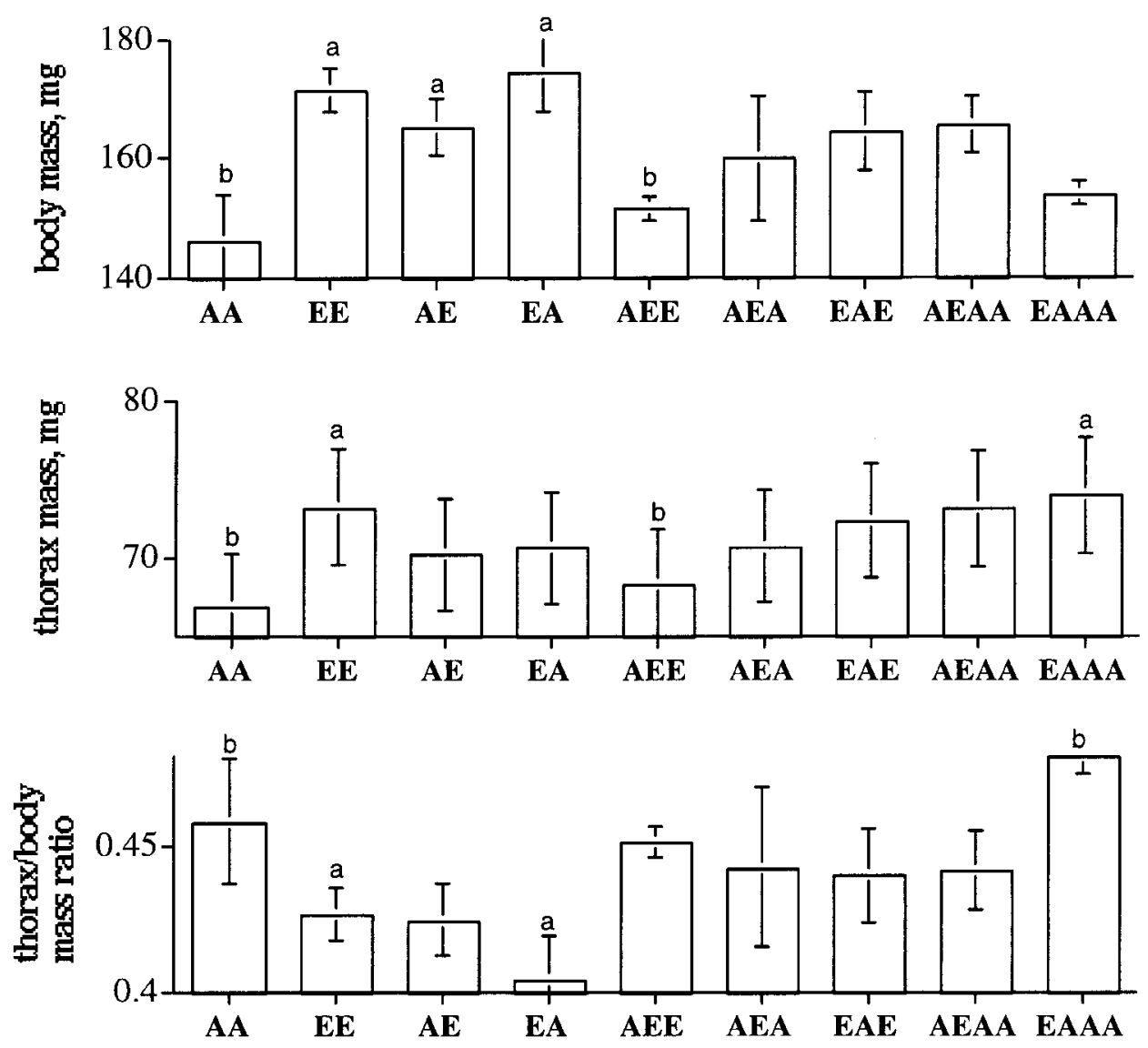

Figure 1. Body masses (top), thorax masses (middle), and thorax/body mass ratios (bottom) of queens of the various lineages. In this and all subsequent figures, mean and SEM are given, and $a$ indicates that the mass for that lineage differed significantly from those of AA bees by a priori comparisons, while $b$ indicates that the lineage differed significantly from EE bees by a priori comparisons. Thorax/body mass ratios were arcsine transformed before statistical analysis.

groups, flight metabolic rate $(\mathrm{mW})$ was significantly affected by lineage $\left(F_{3,50}=3.19, P=0.032\right)$, but body mass was not a significant covariate $(P=0.264)$. With all crosses included, log $\mathrm{mW}$ was also not significantly related to log body mass $\left(F_{1,99}=0.59, P=0.44\right)$. The lineage effects on flight metabolic rate were not confounded by the small variation in chamber temperatures because flight metabolic rates were not correlated with chamber temperature (Pearson's $R=0.09, P>0.3$ ).

\section{Drones}

Body masses $\left(F_{4,91}=12.8, \quad P<0.001\right)$ and thorax masses $\left(F_{4,91}=2.9, P=0.027\right)$ of drones differed significantly among the lineages. For body and thorax masses and thorax/body mass ratios, $\mathrm{A}(\mathrm{A})$ drones were significantly different from $\mathrm{E}(\mathrm{E})$ (Fig. 3). A(A) drones' body masses, thorax masses, and thorax/body mass ratios were $81 \%, 92 \%$, and $114 \%$ of $\mathrm{E}(\mathrm{E})$ values, respectively. Hybrids tended to be intermediate in these parameters, although there was a tendency for hybrid groups to differ significantly from $\mathrm{A}(\mathrm{A})$ but not $\mathrm{E}(\mathrm{E})$ (Fig. 3).

Thorax temperatures differed significantly among the lineages $\left(F_{4,91}=4.7, P=0.002\right)$, with the $\mathrm{A}(\mathrm{A})$ drones significantly hotter than the $\mathrm{E}(\mathrm{E})$ and $\mathrm{E}(\mathrm{A})$ drones (Table 1). Thorax temperatures were not significantly correlated with chamber temperature (Pearson's $R=0.10, P>0.3$ ), indicating that the small variation in chamber temperature did not significantly affect the honeybees' thermal balance. Wing beat frequencies also differed significantly among the lineages $\left(F_{4,87}=3.6, P=\right.$ $0.010)$, with the $\mathrm{A}(\mathrm{A})$ drones significantly higher than the $\mathrm{E}(\mathrm{E})$ and $\mathrm{E}(\mathrm{A})$ drones (Table 1). Thorax temperature was higher by $1.6^{\circ} \mathrm{C}$ and wing beat frequency was higher by $17 \mathrm{~Hz}(8 \%)$ in $\mathrm{A}(\mathrm{A})$ than $\mathrm{E}(\mathrm{E})$ drones.

Body mass-specific metabolic rate $\left(F_{4,91}=6.8, P<0.001\right)$ and thorax mass-specific metabolic rate $\left(F_{4,90}=4.8, P<\right.$ 0.001; Fig. 4) of drones differed among lineages. A(A) drones had a significantly higher body mass-specific metabolic rate 

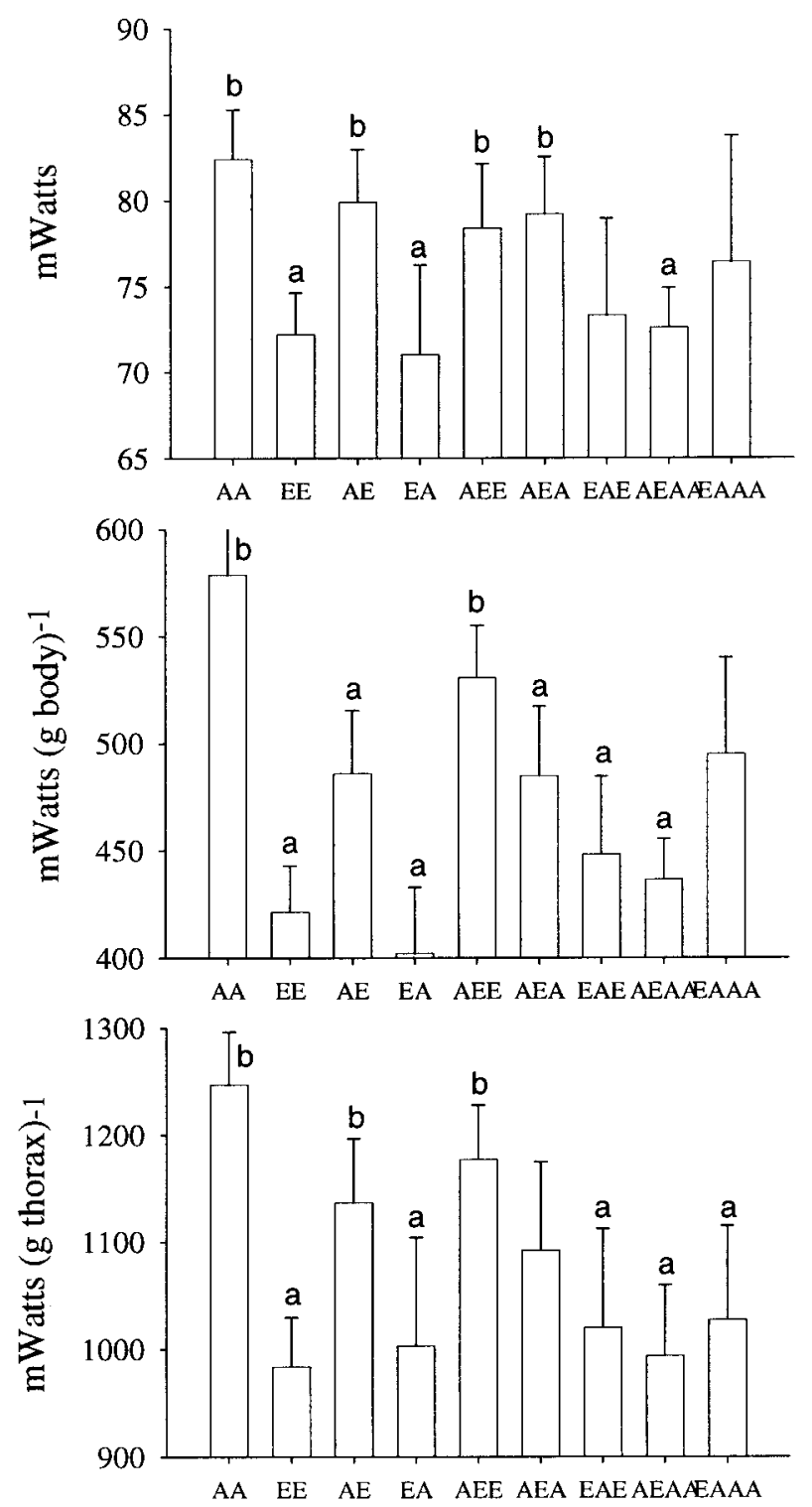

Figure 2. Metabolic rate (top), body mass-specific metabolic rates ( $m i d$ $d l e$ ), and thorax mass-specific metabolic rates (bottom) of queens of the various lineages. See Figure 1 for further definitions.

than the $\mathrm{E}(\mathrm{E}), \mathrm{E}(\mathrm{A})$, and $\mathrm{EA}(\mathrm{A})$ drones, while the $\mathrm{E}(\mathrm{E})$ drones had a significantly lower body mass-specific metabolic rate than the $\mathrm{A}(\mathrm{A})$ and $\mathrm{AE}(\mathrm{A})$ drones. Similar results were found for thorax-specific metabolic rate (Fig. 4). Body mass-specific metabolic rate was 50\% higher and thorax mass-specific metabolic rate was $37 \%$ higher in $\mathrm{A}(\mathrm{A})$ relative to $\mathrm{E}(\mathrm{E})$ drones. As for the queens, there was no evidence that body mass explains the variation in flight metabolic rates among the drones. With drone flight metabolic rate as the dependent variable in a linear regression and all lineages included, body mass was not a significant covariate $(P=0.50)$, but lineage was significant
$(P=0.032)$. Flight metabolic rate was not correlated with chamber temperature (Pearson's $R=0.89, P>0.4$ ).

\section{Discussion}

\section{Lineage Effects on Flight Metabolic Rates}

For both queens and drones, flight metabolic rates $(\mathrm{mW})$ were significantly higher in NAHB relative to EHB (Figs. 2, 4). Body
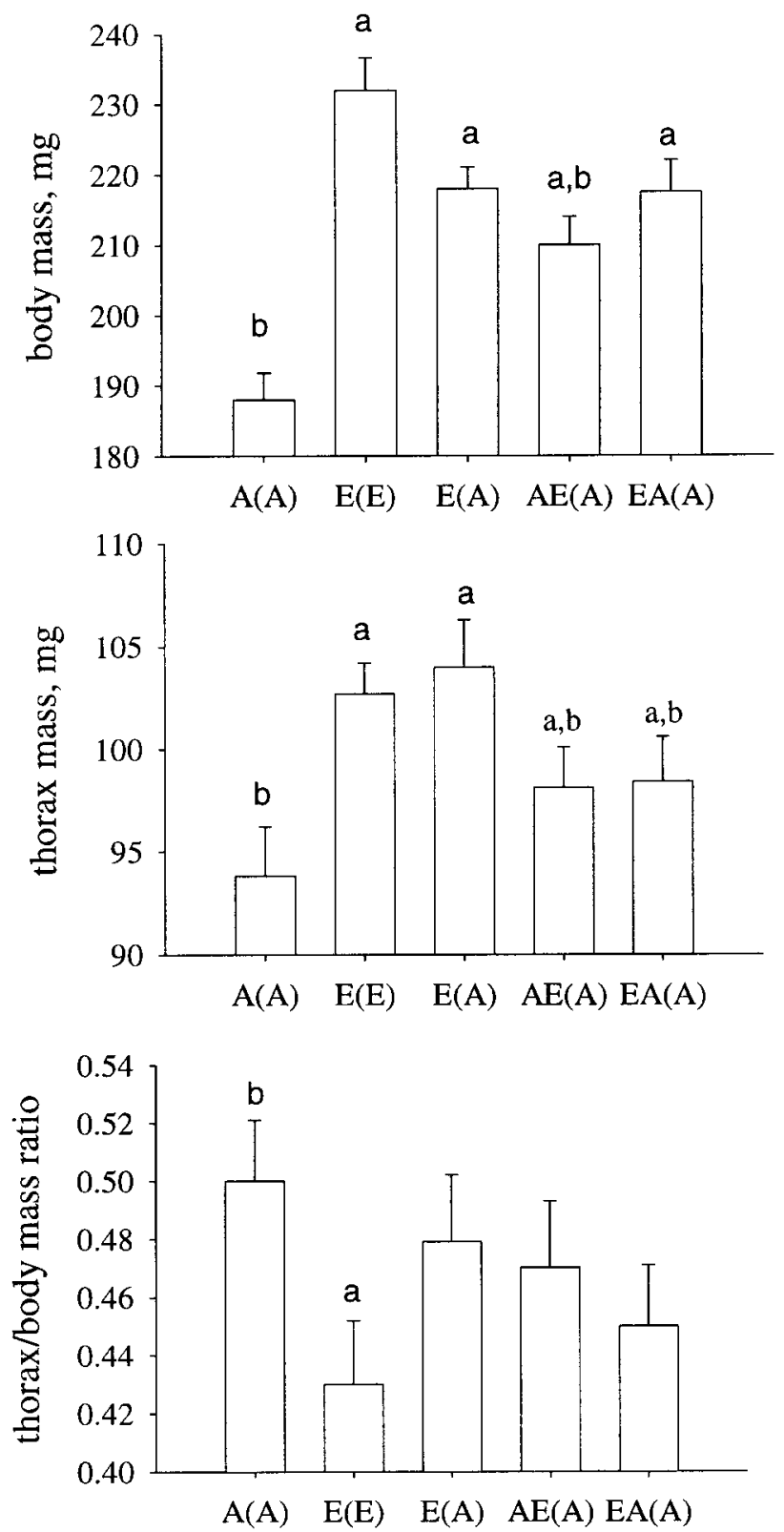

Figure 3. Body masses (top), thorax masses (middle), and thorax/body mass ratios (bottom) of drones of the various lineages. Thorax/body mass ratios were arcsine transformed before statistical analysis. See Figure 1 for further definitions. 

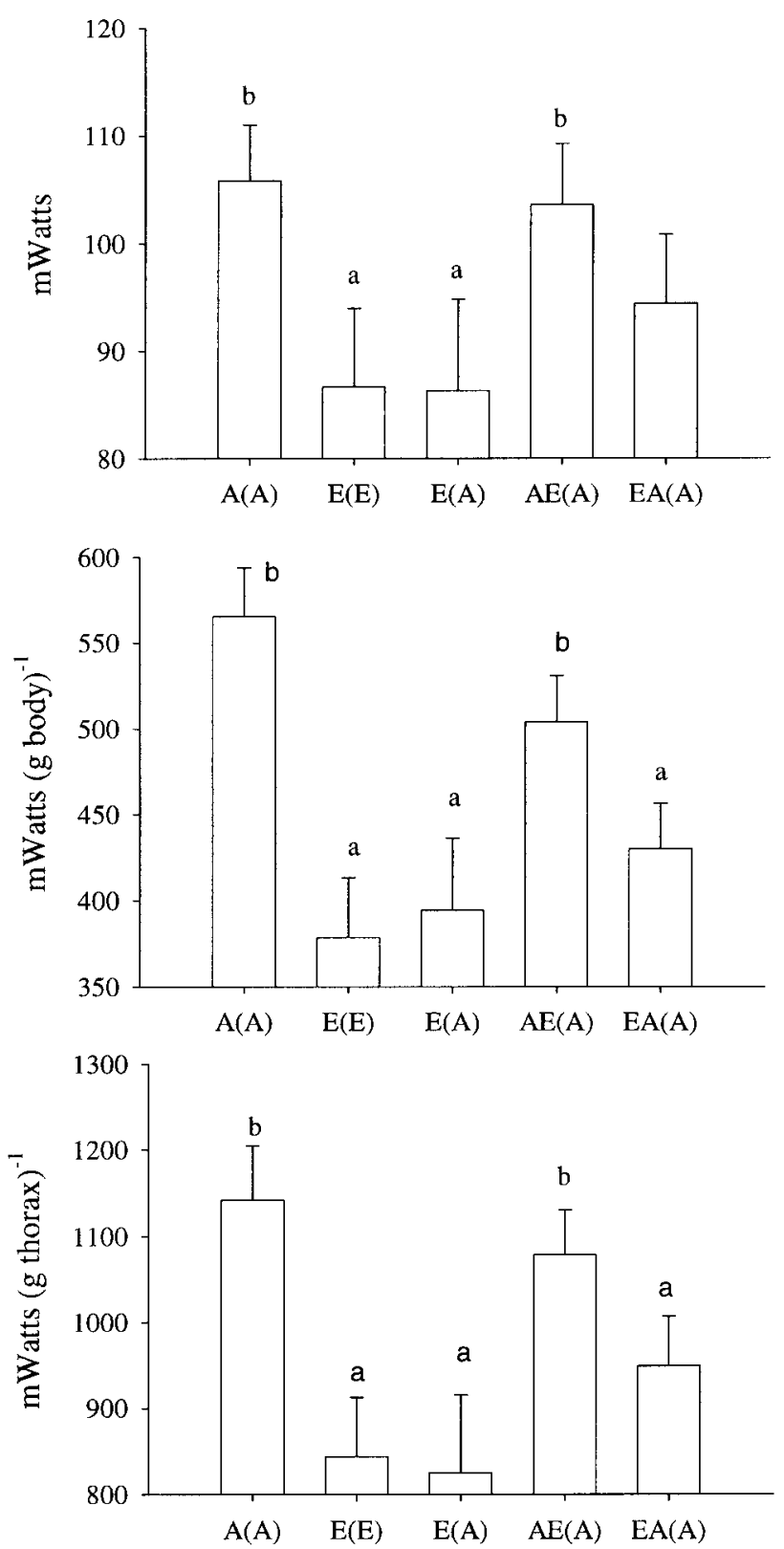

Figure 4. Metabolic rate (top), body mass-specific metabolic rates ( $m i d$ dle), and thorax mass-specific metabolic rates (bottom) of drones of the various lineages. See Figure 1 for further definitions.

mass-specific flight metabolic rates $\left(\mathrm{mW} \mathrm{g}^{-1}\right)$, which should most closely relate to flight performance, were significantly and substantially higher (37\% higher for queens, $50 \%$ higher for drones) for bees with African rather than European lineage (AA vs. $\mathrm{EE}$ for queens, $\mathrm{A}(\mathrm{A})$ vs. $\mathrm{E}(\mathrm{E})$ and $\mathrm{E}(\mathrm{A})$ for drones; Figs. 2, 4). Genetic effects are generally substantiated by the patterns observed in the various crosses; for example, drone $\mathrm{E}(\mathrm{E})$ and E(A) data are very similar for thorax temperatures (Table 1) and flight metabolic rates (Fig. 4). This study substantiates and strengthens our prior conclusion that NAHB have genetically based higher flight metabolic rates than EHB (Harrison and Hall 1993) because NAHB reproductives do not exhibit the possibly confounding greater defensive behavior of workers and because the queens were reared from the egg stage in a common environment.

Body mass-specific flight metabolic rates of hybrid queens suggest negative heterosis for this trait, as found previously for workers (Harrison and Hall 1993). Mass-specific flight metabolic rates $\left(\mathrm{mW} \mathrm{g}^{-1}\right)$ did not appear to increase linearly with the proportion of African lineage; rather, queens with $50 \%$ and 87\% African lineage had metabolic rates significantly lower than those of African queens and not significantly higher than European queens (Fig. 5). Interestingly, nonadditive patterns of inheritance in crosses between NAHB and EHB have also been observed for defensive responses (Stort 1975; Guzman-Novoa and Page 1993, 1994) and queen developmental time (DeGrandi-Hoffman et al. 1998). However, hybrid drones were relatively intermediate in body mass-specific metabolic rate, suggesting that negative heterosis does not occur for this trait in all groups.

Examination of flight metabolic rates $(\mathrm{mW})$ generally does not support negative heterosis. For this parameter, queens from three of the hybrid lineages were intermediate between AA and $\mathrm{EE}$ and not significantly different from AA queens (Fig. 2). Also, the $\mathrm{AE}(\mathrm{A})$ and $\mathrm{EA}(\mathrm{A})$ drones were intermediate in flight metabolic rates, and the $\mathrm{AE}(\mathrm{A})$ drones were significantly higher than $\mathrm{E}(\mathrm{E})$ drones and not significantly different from $\mathrm{A}(\mathrm{A})$ drones (Fig. 4). AE queens had nonsignificantly $(P=0.088)$ higher flight metabolic rates than EA queens (Fig. 2), providing equivocal support for a maternal effect on flight metabolic rate.

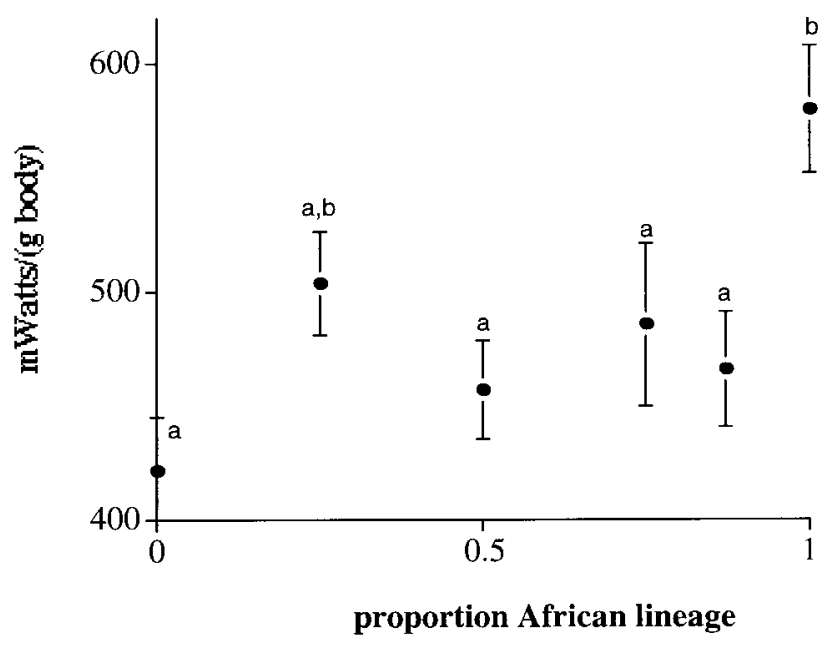

Figure 5. Body mass-specific metabolic rates of honeybee queens, plotted as a function of the proportion of African lineage $(0=$ pure European, $1=$ pure African heritage). See Figure 1 for further definitions. 
Table 2: Pearson correlation matrix for flight physiology variables among the drones

\begin{tabular}{|c|c|c|c|c|}
\hline & Body Mass & Thorax Mass & Thorax Temperature & $\mathrm{mW}(\mathrm{g} \text { body })^{-1}$ \\
\hline Body mass & 1.0 & $.65^{\star}$ & $\ldots$ & $\ldots$ \\
\hline Thorax mass & $.65^{\star}$ & 1.0 & $\ldots$ & $\ldots$ \\
\hline Thorax temperature & -.26 & .08 & 1.0 & $\ldots$ \\
\hline $\mathrm{mW}(\mathrm{g} \text { body })^{-1}$ & -.46 & -.12 & $.65^{\star}$ & 1.0 \\
\hline Wing beat frequency & $-.39^{*}$ & -.28 & $.55^{\star}$ & $.73^{\star}$ \\
\hline
\end{tabular}

Note. Mass-specific flight metabolic rates were positively correlated with wing beat frequencies and thorax temperatures. Wing beat frequencies were inversely correlated with body mass (Bonferroni adjusted probabilities).

* $P<0.001$.

These conflicting results indicate that a larger study with increased sample sizes and number of crosses is necessary to clearly determine the pattern of inheritance of flight metabolic rates in NAHB and $\mathrm{EHB}$ crosses.

Factors Affecting Differences in Flight Metabolic Rates between African and European Bees

How can these genetic factors cause the differences in massspecific flight metabolism? The first likely factor that may explain the higher body mass-specific metabolic rates in African reproductives is a genetically based higher thorax/body mass ratio (7\% higher in queens, $14 \%$ higher in drones). This morphological difference can theoretically account for $19 \%$ and $28 \%$ of the greater body mass-specific metabolic rates of NAHB queens and drones, respectively. Similarly, workers of African honeybee subspecies averaged $20 \%$ higher thorax/body mass ratios than European subspecies, as well as lower wing loading (Hepburn et al. 1999). It would be interesting to examine the basis of these differences in thorax/body mass ratio. Do Africanized reproductives carry smaller reproductive organs or energy stores?

A second mechanism by which genetic factors appear to cause differences in flight metabolic rates between NAHB and EHB was a higher thorax-specific metabolic rate. Thoraxspecific metabolic rates were $20 \%-25 \%$ higher in NAHB relative to EHB. At present, it is unclear whether these higher thorax-specific metabolic rates relate to differences in flight muscle mass, flight muscle-specific aerobic capacity, or simply a higher degree of behavioral activation.

Smaller insects often have higher mass-specific metabolic rates during hovering flight than larger animals (Casey 1989). Can the differences in flight metabolic rates between NAHB and EHB be explained by allometric scaling? For both the queens and drones, log metabolic rates $(\mathrm{mW})$ were not significantly correlated with log body mass, strongly arguing against the hypothesis that the variation in body mass explains the variation in metabolic rates we observed among these honeybee lineages. However, an experimental test of this hypothesis, perhaps by using comb size to manipulate body size within bee races, would be very welcome.
Correlations between Metabolic Rate and Thorax Temperatures

Despite being smaller, African drones had thorax temperatures that were $1.6^{\circ} \mathrm{C}$ hotter than European drones, and metabolic rates were positively correlated with thorax temperatures (Table 2 ). Comparative studies across bee species have shown that thorax temperature during flight tends to be constant or increase with increasing body size (Roberts and Harrison 1998), the opposite trend to that observed here. These data suggest that the greater flight metabolic rate of the NAHB drones allows them to achieve higher thorax temperatures than EHB or hybrid drones despite their smaller body sizes.

\section{Flight Metabolic Rate and Flight Performance}

An insect with a relatively high flight metabolic rate could be a low-efficiency organism (with a high cost to perform a task such as hovering), a high-output organism (producing greater mechanical power output), or both. Among the drones used in this study, high flight metabolic rates were correlated with higher wing beat frequencies (Tables 1,2), supporting the hypothesis that African bees produced greater power output during flight. However, measurement of power output minimally requires measurement of wing stroke amplitude, stroke plane and body angles, and aspects of wing morphology (Dudley 2000). Thus, without direct measures of flight speeds, accelerations, wing stroke amplitude, and so forth, it is impossible to know whether the higher flight metabolic rates of the African bees were associated with higher flight mechanical power outputs. However, in the fruit fly Drosophila melanogaster (Dickinson and Lighton 1995; Lehmann and Dickinson 1997) and the carpenter bee Xylocopa veripuncta (Roberts et al. 2004), metabolic rate is strongly correlated with mechanical power output during flight, suggesting that the higher flight metabolic rates of NAHB may enhance their flight performance relative to $\mathrm{EHB}$, with possible effects on mating performance and dispersal.

It is interesting that correlated metabolic, flight performance, and life span differences are also found among different species of Apis, with some species exhibiting higher heat production rates, shorter life spans, and faster flight speeds than others 
(Dyer and Seeley 1987). These correlations observed across Apis species and perhaps within Apis mellifera suggest another genetic mechanism by which Africanized bees might outcompete Europeans in the Neotropics; perhaps there are genes that have pleiotropic effects on rate processes, including development, flight metabolism, flight behavior, and life span in bees.

\section{Conclusions}

Reproductives of Africanized honeybees have higher massspecific flight metabolic rates than European strains, and these differences appear to be genetically based. In particular, these genes appear to influence thorax/body mass ratios and thoraxspecific metabolic rate. The functional significances of these differences are unclear, but our results predict that Africanized bees will have superior mass-specific flight performance relative to European bees. As previously found for workers, there is some evidence for negative heterosis for flight metabolic rate in crosses between Africanized and European reproductives. If differences in flight performance are demonstrated, it would be very interesting to test whether these genetic/physiological differences contribute to explaining why Africanized bees outcompete hybrid bees over time in most semitropical locations.

\section{Acknowledgments}

This study was partially supported by National Science Foundation (NSF) IBN-9317784, NSF IBN-0093410, and an Arizona State Faculty Grant-in-Aid award to J.F.H.; by NSF BSR9007681 to O.R.T.; and by grants from the USDA National Research Initiative Competitive Grants Program to H.G.H. We thank Gordon Johnston, Felipe Brizuela, and Phil Waclawski for help with the experiments. The article was much improved by three anonymous reviewers, who we appreciate.

\section{Literature Cited}

Casey T.M. 1989. Oxygen consumption during flight. Pp. 257272 in G.J. Goldsworthy and C.H. Wheeler, eds. Insect Flight. CRC, Boca Raton, FL.

DeGrandi-Hoffman G., J.C. Watkins, A.M. Collins, G.M. Loper, J.H. Martin, M.C. Arias, and W.S. Sheppard. 1998. Queen developmental time as a factor in the Africanization of European honey bee (Hymenoptera: Apidae) populations. Ann Entomol Soc Am 91:52-58.

Del Lama M.A., J.A. Lobo, A.E.E. Soares, and S.N. Del Lama. 1990. Genetic differentiation estimated by isozymic analysis of Africanized honeybee populations from Brazil and from Central America. Apidologie 21:271-280.

Dickinson M.H. and J.R.B. Lighton. 1995. Muscle efficiency and elastic storage in the flight motor of Drosophila. Science 268:87-90.
Dudley R. 2000. The Biomechanics of Insect Flight: Form, Function, Evolution. Princeton University Press, Princeton, NJ.

Dyer F.C. and T.D. Seeley. 1987. Interspecific comparisons of endothermy in honey-bees (Apis): deviations from the expected size-related patterns. J Exp Biol 127:1-26.

Fewell J. and J.F. Harrison. 2002. Variation in foraging phenotypes between African and European honey bee workers. Pp. 3-15 in R.E. Page and E. Erickson, eds. Proceedings of the 2nd International Congress on Africanized Honey Bees and Bee Mites. A.I. Root, New York.

Garland T. and P.A. Carter. 1994. Evolutionary physiology. Annu Rev Physiol 56:579-621.

Guzman-Novoa E. and R.E. Page. 1993. Backcrossing Africanized honey bee (Apis mellifera L.) queens to European drones reduces colony defensive behavior. Ann Entomol Soc Am 86:352-355.

. 1994. Genetic dominance and worker interactions affect honeybee colony defense. Behav Ecol Sociobiol 5:791797.

Hall H.G. 1986. DNA differences found between Africanized and European honeybees. Proc Natl Acad Sci USA 83:48744877.

-1992a. DNA studies reveal processes involved in the spread of New World African honeybees. Fla Entomol 75: 51-59.

- 1992b. Further characterization of nuclear DNA RFLP markers that distinguish African and European honeybees. Arch Insect Biochem Physiol 19:163-175.

Hall H.G. and K. Muralidharan. 1989. Evidence from mitochondrial DNA that African honey bees spread as continuous maternal lineages. Nature 339:211-213.

Hall H.G. and D.R. Smith. 1991. Distinguishing African and European honeybee matrilines using amplified mitochondrial DNA. Proc Natl Acad Sci USA 88:4548-4552.

Harrison J.F. and J.H. Fewell. 2002. Environmental and genetic influences on flight metabolic rate in the honey bee, Apis mellifera. Comp Biochem Physiol A 133:323-333.

Harrison J.F. and H.G. Hall. 1993. African-European honeybee hybrids have low nonintermediate metabolic capacities. Nature 363:258-260.

Harrison J.F., D.I. Nielsen, and R.E. Page. 1996. Malate dehydrogenase phenotype, temperature and colony effects on flight metabolic rate in the honey-bee, Apis mellifera. Funct Ecol 10:81-88.

Hepburn H.R., S.E. Radloff, and S. Fuchs. 1999. Flight machinery dimensions of honeybees, Apis mellifera. J Comp Physiol B 169:107-112.

Kerr W.E. and D. Bueno. 1970. Natural crossing between Apis mellifera adansonii and Apis mellifera ligustica. Evolution 24: 145-155.

Lehmann F.O. and M.H. Dickinson. 1997. The changes in power requirements and muscle efficiency during elevated 
force production in the fruit fly Drosophila melanogaster. J Exp Biol 200:1133-1143.

Lobo J.A., M.A. Del Lama, and M.A. Mestriner. 1989. Population differentiation and racial admixture in the Africanized honeybee (Apis mellifera L.). Evolution 43:794-802.

McMichael M. and H.G. Hall. 1996. DNA RFLPs at a highly polymorphic locus distinguish European and African subspecies of the honey bee Apis mellifera L. and suggest geographical origins of New World honey bees. Mol Ecol 5:403416.

Michener C.D. 1975. The Brazilian bee problem. Annu Rev Entomol 20:399-416.

Page R.E. 1989. Evolution: Neotropical African bees. Nature 339:181-182.

Richardson B.J., P.R. Baverstock, and M. Adams. 1986. Allozyme Electrophoresis: A Handbook for Animal Systematics and Population Studies. Academic Press, New York.

Rinderer T.E., J.A. Stelzer, B.P. Oldroyd, S.M. Buco, and W.L. Rubink. 1991. Hybridization between European and Africanized honey bees in the Neotropical Yucatan Peninsula. Science 253:309-311.

Roberts S.P. and J.F. Harrison. 1998. Mechanisms of thermoregulation in flying bees. Am Zool 38:492-502.

Roberts S.P., J.F. Harrison, and R. Dudley. 2004. Allometry of kinematics and energetics in carpenter bees (Xylocopa varipuncta) hovering in variable-density gases. J Exp Biol 207: 993-1004.

Rothe U. and W. Nachtigall. 1989. Flight of the honey bee. IV. Respiratory quotients and metabolic rates during sitting, walking and flying. J Comp Physiol B 158:739-749.

Schneider S.S. 1995. Swarm movement patterns inferred from waggle dance activity of the Neotropical African honey bee in Costa Rica. Apidologie 26:395-406.

Sheppard W.S., T.E. Rinderer, J.A. Mazzoli, J.A. Stelzer, and H. Shimanuki. 1991. Gene flow between African- and European-derived honey bee populations in Argentina. Nature 349:782-784.

Smith D.R., O.R. Taylor, and W.M. Brown. 1989. Neotropical Africanized honey bees have African mitochondrial DNA. Nature 339:213-215.
Southwick E.E. 1990. Comparative energy balance in groups of Africanized and European honey bees: ecological implications. Comp Biochem Physiol 97:1-8.

Spivak M., D.J.C. Fletcher, and M.D. Breed. 1990. The "African” Honey Bee. Westview, Boulder, CO.

Spivak M., T. Ranker, O.R. Taylor, W. Taylor, and L. Davis. 1988. Discrimination of Africanized honey bees using behavior, cell size, morphology and a newly discovered isozyme polymorphism. Pp. 313-324 in G.R. Needham, R.E. Page, M. Delfinado-Baker, and C.E. Bowman, eds. Africanized Honey Bees and Bee Mites. Elis Horwood, Chichester.

Stort A.C. 1975. Genetic study of the aggressiveness of two subspecies of Apis mellifera in Brazil. II. Time at which the first sting reached the leather ball. J Apic Res 14:171-175.

Suazo A., R. McTiernan, and H.G. Hall. 1998. Differences between African and European honey bees (Apis mellifera L.) in random amplified polymorphic DNA (RAPD). J Hered 89:32-36.

Taylor O.R. 1985. African bees: potential impact in the United States. Bull Entomol Soc Am 31:14-24.

- 1999. Genetic replacement of European honey bee (Apis mellifera) subspecies by invading African bees in the Americas. Pp. 189-210 in E. Yano, K. Matsuo, M. Shiyomi, and D.A. Andow, eds. Proceedings of the International Workshop on Biological Invasions of Ecosystems by Pests and Beneficial Organisms. NIAES Series 3. Tsukuba.

Wilkinson L. 1989. SYSTAT: The System for Statistics. SYSTAT, Evanston, IL.

Winston M.L. 1992a. The biology and management of Africanized honey bees. Annu Rev Entomol 37:395-406.

- 1992b. Killer Bees: The African Honey Bee in the Americas. Harvard University Press, Cambridge, MA.

Winston M.L. and S.J. Katz. 1981. Longevity of cross-fostered honeybee workers (Apis mellifera) of European and Africanized races. Can J Zool 59:1571-1575.

. 1982. Foraging differences between cross-fostered honeybee workers (Apis mellifera) of European and Africanized races. Behav Ecol Sociobiol 10:125-129. 